\title{
Unintentional Injury and Social Correlates among In-School Adolescents in Seven Caribbean Countries
}

\author{
Karl Peltzer \\ ASEAN Institute for Health Development, Madidol University, Salaya, Phutthamonthon, Nakhonpathom, Thailand, 73170., \\ University of Limpopo, Turfloop Campus, Sovenga 0727, South Africa., HIVIAIDS/STIs/and TB (HAST), \\ Human Sciences Research Council, Private Bag X41, Pretoria 0001, South Africa \\ Email:karl.pel@mahidol.ac.th

\section{Supa Pengpid} \\ ASEAN Institute for Health Development, Madidol University, Salaya, Phutthamonthon, Nakhonpathom, \\ Thailand, 73170.University of Limpopo, Turfloop Campus, Sovenga 0727, South Africa
}

\section{Doi:10.5901/mjss.2014.v5n20p2321}

\begin{abstract}
The aim of this study was to assess estimates of the prevalence and social correlates of unintentional injury among adolescents in the Caribbean. Cross-sectional national data from the Global School-based Health Survey (GSHS) included 11571 students from seven Caribbean countries chosen by a two-stage cluster sample design to represent all students in grades 6-10 in each country. The percentage of adolescents reporting one or more serious injuries within the past 12 months was $54.3 \%$ for all countries, ranging from $43.1 \%$ in Dominica to $59.5 \%$ in Jamaica. By major activity of all survey participants, "fall" (11.4\%) was the leading external cause of injury, followed by fighting (5.0\%), "something fell on me or hit me"(4.9\%) and vehicle accident (4.3\%). In multivariate regression analysis it was found that being male, having hunger (as an indicator for low socioeconomic status), substance use (smoking and alcohol use), psychological distress (anxiety or worried and suicide ideation) and truancy were found to be associated with annual injury prevalence rates. Several risk factors were identified which can be utilized in reaching these young people for change strategies in injury prevention programmes.
\end{abstract}

Keywords: injury, social correlates, school children, Antigua and Berbuda, Dominica, Grenada, Jamaica, Saint Lucia, Saint Vincent and the Grenadines, Trinidad and Tobago

\section{Introduction}

Unintentional injuries among 1-19-year olds accounted for $12 \%$ of 5.1 million global deaths from injuries in 2010 (Alonge \& Hyder, 2014), with a higher proportion occurring in low- and middle-income countries (Balan \& Lingam, 2012). Among 13 to 15 year-olds in six African countries the annual prevalence of serious injuries were $68.2 \%$ (Peltzer, 2008). Ricketts, Bergeron, Emmanuel and Smith (2010) note that "violence and injuries have become a huge burden on the state and society throughout the Caribbean." and Perel, Casas, Ortiz and Miranda (2006) call for action to attend to injuries and non-communicable diseases in the Caribbean. There is a lack of information on injury in adolescents in Caribbean countries (Anatol, 1985; Ramroop et al., 2009; St Bernard \& Matthews, 2003; Ward et al., 2010).

Childhood injuries may be related to human and environmental factors (Pickett et al., 2005) including socioeconomic status (male gender, lower economic status) (Balan \& Lingam, 2012), behavioural (substance use) factors (Mytton, Towner, Brussoni, \& Gray, 2009; Pickett et al., 2002), psychological distress (Mytton et al., 2009; Pickett et al., 2002), home and school environment (Mytton et al., 2009). There is a lack of national data regarding injury and its social correlates among in-school adolescents in the Caribbean. Therefore, the aim of this study was to determine estimates of the prevalence and social correlates of injury among adolescents in seven Caribbean countries.

\section{Method}

\subsection{Participants and procedures}

This study involved secondary analysis of existing data from the Global School-Based Health Survey (GSHS) from seven 
Caribbean countries (Antigua and Berbuda, Dominica, Grenada, Jamaica, Saint Lucia, Saint Vincent and the Grenadines, Trinidad and Tobago). Details and data of the GSHS can be accessed at http://www.who.int/chp/gshs/methodology len/index.html. The GSHS school-based survey used a two-stage (schools and classes) cluster sample design to collect data to represent all students in grades 6 to 10 in each country. Students completed the self-administered questionnaire during one classroom period under the supervision of trained survey administrators (CDC, 2010).

\subsection{Measures}

Injury. "During the past 12 months, how many times were you seriously injured?" (Serious injury was defined as "when it makes you miss at least one full day of usual activities (such as school, sports, or a job) or requires treatment by a doctor or nurse)." A response of "0" indicated as not having sustained a serious injury, while a response of one or more times was classified as having experienced a serious injury. Additional items on injury included close-ended questions that addressed external cause (During the past 12 months, what was the major cause of the most serious injury that happened to you?), and type of injury (During the past 12 months, what was the most serious injury that happened to you?) (CDC, 2010)

Hunger: A measure of hunger was derived from a question reporting the frequency that a young person went hungry because there was not enough food at home in the past 30 days (response options were from $1=$ never to $5=$ always) (coded $1=$ most of the time or always and $0=$ never, rarely or sometimes) (CDC, 2010).

\subsubsection{Substance use variables}

Smoking cigarettes: "During the past 30 days, on how many days did you smoke cigarettes?" (Response options were from $1=0$ days to $7=a l l ~ 30$ days) (Coded $1=1$ or 2 to all 30 days, and $0=0$ days). Alcohol use: "During the past 30 days, on how many days did you have at least one drink containing alcohol? Response options ranged from $1=0$ days to $7=a l l ~ 30$ days; Coded $1=3-5$ days to all 30 days, and $0=0-1$ or 2 days. (CDC, 2010)

\subsubsection{Psychological distress}

Psychological distress was assessed with 4 items. Loneliness: "During the past 12 months, how often have you felt lonely?" (Response options were from $1=$ =never to $5=a$ always) (Coded $1=$ most of the time or always and $0=$ never, rarely or sometimes). Suicide ideation: "During the past 12 months, did you ever seriously consider attempting suicide?" (Response option was $1=y e s$ and $2=$ no, coded $1=1,2=0$ ). No close friends: "How many close friends do you have?" (Response options $1=0$ to $4=3$ or more, coded $1=1,2-4=0$.). Anxiety or worried: "During the past 12 months, how often have you been so worried about something that you could not sleep at night?" (Response options were from 1=never to $5=$ always) (Coded $1=$ most of the time or always and $0=$ never, rarely or sometimes). (CDC, 2010)

\subsubsection{Protective Factors}

Protective factors were assessed with five items on school attendance, peer support at school, parental or guardian supervision, connectedness, and bonding. School attendance: "During the past 30 days, on how many days did you miss classes or school without permission?" (coded $1=0$ times and $0=1$ or 2 to 10 or more times). Peer support at school was assessed with the question "During the past 30 days, how often were most of the students in your school kind and helpful?" Parental or guardian supervision "During the past 30 days, how often did your parents or guardians check to see if your homework was done"? Parental or guardian connectedness "During the past 30 days, how often did your parents or guardians understand your problems or worries?" and Parental or guardian bonding "During the past 30 days, how often did your parents or guardians really know what you were doing with your free time?" Response options to these questions were from $1=$ never to $5=$ always, coded $1=$ never or rarely and $0=$ sometimes to always. $(C D C, 2010)$

\subsection{Data analysis}

Data analysis was performed using STATA software version 11.0 (Stata Corporation, College Station, Texas, USA). This software has the advantage of directly including robust standard errors that account for the sampling design, i.e. cluster sampling owing to the sampling of school classes. In further analysis, the injury risk variable was recoded into two categories: not injured (0); injured at least once (1). Associations between potential risk factors and injuries among school 
children were evaluated calculating odds ratios (OR). Logistic regression was used for evaluation of the impact of explanatory variables on risk for injury (binary dependent variable). The dependent variable was the injury event, and the independent variables were factors which significantly increased injury risk in the univariate analysis. For the individual risk behaviour analyses, crude and adjusted odds ratios (ORs) and associated 95\% confidence intervals were calculated for each level of exposure.

In the analysis, weighted percentages are reported. The reported sample size refers to the sample that was asked the target question. The two-sided 95\% confidence intervals are reported. The p-value less or equal to $5 \%$ is used to indicate statistical significance. Both the reported 95\% confidence intervals and the p-value are adjusted for the multistage stratified cluster sample design of the study.

\section{Results}

\subsection{Sample characteristics}

The sample included 11571 students (Mean age 14.5 years) from Caribbean countries; there were slightly more male (50.4\%) than female students (49.6\%) and the majority of the students (79.0\%) were attending school grades 7 to 9 . Data from the different countries had been selected from 2007 to 2010 (see Table 1). The overall response rate, a product of school and student response rates, varied from $67 \%$ in Antigua and Berbuda to $90 \%$ in Trinidad and Tobago.

Table 1: Sample response rate and age distribution of students surveyed; GSHS 2007-2010.

\begin{tabular}{|l|c|c|c|c|c|}
\hline Country & $\begin{array}{c}\text { Survey } \\
\text { sample }\end{array}$ & $\begin{array}{c}\text { Survey } \\
\text { year }\end{array}$ & $\begin{array}{c}\text { Overall } \\
\text { response rate* }\end{array}$ & $\begin{array}{c}\text { Boys in } \\
\text { final sample }\end{array}$ & $\begin{array}{c}\text { Mean age of } \\
\text { final sample }\end{array}$ \\
\hline & $\mathrm{N}$ & & $\%$ & $\%$ & Mean \\
\hline Antigua and Berbuda & 1186 & 2009 & 67.0 & 51.5 & 14.0 \\
\hline Dominica & 1642 & 2009 & 84.0 & 51.2 & 14.1 \\
\hline Grenada & 1542 & 2008 & 78.0 & 44.9 & 14.1 \\
\hline Jamaica & 1623 & 2010 & 72.0 & 51.4 & 14.7 \\
\hline Saint Lucia & 1276 & 2007 & 82.0 & 49.1 & 14.1 \\
\hline Saint Vincent and the Grenadines & 1333 & 2007 & 84.0 & 47.3 & 13.7 \\
\hline Trinidad and Tobago & 2969 & 2007 & 90.0 & 49.8 & 14.2 \\
\hline All & 11571 & & & 50.4 & 14.5 \\
\hline
\end{tabular}

*Overall response rate, the product of school and the student response rate

\subsection{Descriptive results}

The percentage of adolescents reporting one or more serious injuries within the past 12 months was $54.3 \%$ for all countries, ranging from $43.1 \%$ in Dominica to $59.5 \%$ in Jamaica, and it has been more often in boys (58.9\%) than girls (48.7\%). Estimates of adolescents reporting a single injury were less variable, ranging from $20.6 \%$ in Dominica to $27.5 \%$ in Jamaica, while slightly greater differences in prevalence estimates by country were found in the number of adolescents reporting multiple injuries, ranging from $22.4 \%$ in Dominica to $31.9 \%$ in Jamaica, respectively. By major activity of all survey participants, "fall" (11.4\%) was the leading external cause of injury, followed by fighting with someone (5.0\%), "something fell on me or hit me"(4.9\%), vehicle accident (4.3\%), and attacked or assaulted or abused by someone (1.9\%). The injury sustained by most students of all surveyed involved a cut, puncture, stab wound (9.5\%), followed by broken bone/dislocated joint (7.8\%), concussion/head injury (2.7\%), burn injury (1.5\%) and had a gunshot wound (1.4\%) (see Table 2). 
Table 2: Annual prevalence of injury events by sex and country in percent

\begin{tabular}{|c|c|c|c|c|c|c|c|c|c|c|}
\hline Variable & 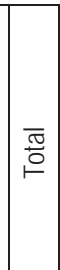 & ठิ) & $\stackrel{\infty}{\frac{\infty}{5}}$ & 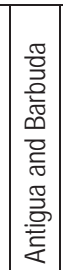 & 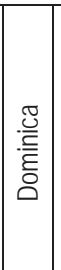 & $\begin{array}{l}\frac{\pi}{0} \\
\frac{\pi}{0} \\
\frac{0}{U}\end{array}$ & 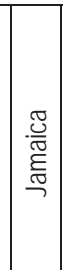 & 乐 & 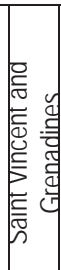 & 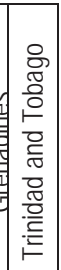 \\
\hline INJURY (in the past 12 months) & 54.3 & 58.9 & 48.7 & 50.3 & 43.1 & 48.6 & 59.5 & 46.2 & 48.8 & 47.9 \\
\hline Injured once & 25.1 & 25.4 & 24.4 & 24.5 & 20.62 & 25.6 & 27.5 & 22.6 & 23.9 & 21.4 \\
\hline Injured more than once & 29.2 & 33.5 & 24.3 & 25.7 & 22.42 & 423.0 & 31.9 & 23.6 & 24.9 & 26.5 \\
\hline CAUSE (of most serious injury) & & & & & & & & & & \\
\hline I was in a motor vehicle accident or hit by a motor vehicle & 4.3 & 6.3 & 2.4 & 2.8 & 2.3 & 2.2 & 6.3 & 1.8 & 2.5 & 2.6 \\
\hline $\mid$ fell & 11.4 & 10.8 & 11.9 & 11.5 & 9.91 & 12.7 & 10.7 & 14.4 & 12.0 & 11.7 \\
\hline Something fell on me or hit me & 4.9 & 6.1 & 3.7 & 4.5 & 2.1 & 3.2 & 5.8 & 2.5 & 3.9 & 4.8 \\
\hline I was fighting with someone & 5.0 & 5.8 & 4.2 & 4.8 & 2.6 & 2.3 & 6.2 & 2.5 & 3.8 & 3.5 \\
\hline I was attacked or assaulted or abused by someone & 1.9 & 1.9 & 1.9 & 0.5 & 0.7 & 2.3 & 2.3 & 0.9 & 1.3 & 1.6 \\
\hline I was in a fire or too near a flame or something hot & 0.9 & 0.8 & 1.0 & 1.6 & 0.8 & 0.6 & 1.2 & 0.4 & 1.5 & 0.4 \\
\hline Something else caused my injury & 14.9 & 15.2 & 14.7 & 17.5 & 14.3 & 16.8 & 14.2 & 18.5 & 14.8 & 15.8 \\
\hline TYPE OF INJURY (of most serious injury) & & & & & & & & & & \\
\hline I had a broken bone or a dislocated joint & 7.8 & 10.4 & 5.5 & 6.8 & 5.3 & 9.4 & 7.1 & 9.6 & 9.3 & 13.7 \\
\hline I had a cut, puncture, or stab wound & 9.5 & 12.0 & 7.0 & 9.8 & 7.5 & 5.6 & 12.2 & 5.9 & 7.4 & 4.0 \\
\hline I had a concussion or other head or neck injury, was knocked out, or could not breath & 2.7 & 2.5 & 2.9 & 3.9 & 2.1 & 4.4 & 5.1 & 5.0 & 4.2 & 4.5 \\
\hline I had a gunshot wound & 1.4 & 2.3 & 0.5 & 0.8 & 1.2 & 0.9 & 1.8 & 0.9 & 1.3 & 1.5 \\
\hline I had a bad burn & 1.5 & 1.1 & 1.9 & 1.8 & 1.4 & 3.7 & 2.8 & 3.3 & 4.3 & 3.0 \\
\hline I lost all or part of a foot, leg, hand, or arm & 0.2 & 0.2 & 0.1 & 0.3 & 0.6 & 4.5 & 0.7 & 3.3 & 3.4 & 2.8 \\
\hline Something else happened to me & 15.4 & 14.9 & 15.8 & 19.7 & 16.9 & 13.4 & 17.9 & 14.2 & 211.1 & 12.1 \\
\hline
\end{tabular}

\subsection{Associations with annual injury prevalence}

In multivariate logistic regression it was found that being male, having hunger (as an indicator for low economic status), substance use (smoking and alcohol use), psychological distress (anxiety or worried and suicide ideation) and truancy were found to be associated with annual injury prevalence rates (see Table 3).

Table 3. Logistic regression analysis for association between risk behaviours and injury (overall analysis for all injury types)

\begin{tabular}{|l|c|c|}
\hline Variables (\%) & Crude Odds ratio (95\% Cl) & Adjusted Odds ratio (95\% Cl) \\
\hline Age in years & 1.00 & \\
13 or less & $1.21(0.98-1.50)$ & \\
14 & $1.06(0.82-1.36)$ & \\
15 & $1.07(0.67-1.71)$ & \\
16 or more & 1.00 & \\
\hline Gender & $1.51(1.22-1.87)^{\star \star \star}$ & $1.34(1.08-1.67)^{\star \star}$ \\
Female & $3.34(2.28-4.89)^{\star \star \star}$ & $1.82(1.00-3.32)^{\star}$ \\
\hline Male & & \\
\hline Hunger (7.2\%) & $3.82(2.82-5.17)^{\star \star \star}$ & $2.34(1.84-2.99)^{\star \star \star}$ \\
\hline Substance use & $2.01(1.51-2.69)^{\star \star \star}$ & $1.48(1.21-1.82)^{\star \star \star}$ \\
\hline Current smoking (9.8\%) & & \\
\hline Current drinking (at least 3 days/month) (22.1\%) & $1.68(1.27-2.24)^{\star \star \star}$ & $1.18(0.78-1.77)$ \\
\hline Psychological distress & $2.70(1.97-3.67)^{\star \star \star}$ & $2.00(1.41-2.84)^{\star \star \star}$ \\
\hline Loneliness (14.7\%) & $2.13(1.86-2.43)^{\star \star \star}$ & $1.44(1.16-1.79)^{\star \star \star}$ \\
\hline Anxiety or worried (12.5\%) & & \\
\hline Suicide ideation (19.9\%) & & \\
\hline
\end{tabular}




\begin{tabular}{|l|c|c|}
\hline No close friend (9.3\%) & $1.12(0.73-1.73)$ & --- \\
\hline Protective factors & & $0.60(0.46-0.78)^{\star \star \star}$ \\
\hline School attendance (72.8\%) & $0.38(0.30-0.48)^{\star \star \star}$ & $\cdots$ \\
\hline Peer support (21.3\%) & $1.06(0.81-1.39)$ & $\cdots$ \\
\hline Parental or guardian supervision (35.7\%) & $1.17(0.92-1.48)$ & --- \\
\hline Parental or guardian connectedness (32.7\%) & $1.13(0.86-1.48)$ & $1.08(0.84-1.38)$ \\
\hline Parental or guardian bonding (41.9\%) & $0.77(0.62-0.96)^{\star}$ & \\
\hline
\end{tabular}

\section{Discussion and Conclusion}

In this study of in-school adolescents in 7 Caribbean countries using the Global School Health Survey of 2007-2010, a high percentage of adolescents (54.3\%) reported one or more serious injuries within the past 12 months. This annual prevalence of severe injury was still lower than among school children in six African countries (68.2\%) (Peltzer, 2008) and higher than in four Southeast Asian countries (42.2\%) (Peltzer \& Pengpid, 2012). The study found some country variation of annual injury prevalence, with Jamaica having the highest figures (59.5\%). Injuries are among the leading causes of death in Jamaica (Hasbrouck, Durant, Ward, \& Gordon, 2002). Regarding the cause of the injury, among the different study countries Jamaica also had the highest prevalence for fights and having been in a motor vehicle accident or hit by a motor vehicle. Previous studies have also found high rates of interpersonal violence among high school students, adolescents and in the general population in Jamaica (Arscott-Mills, Gordon, McDonald, \& Holder, 2002; Le Franc, Samms-Vaughan, Hambleton, Fox, \& Brown, 2008; Soyibo \& Lee, 2000). In agreement with other studies (e.g. Pickett et al., 2006) this study found that "fall" was the leading external cause of injury.

Further, the study found that male gender and low economic background were associated with the occurrence of injury, as found in a review by Balan and Lingam (2012). Substance usages (smoking and alcohol use) and psychological distress (anxiety or worried and suicide ideation) were, as in previous studies (Mytton et al., 2009; Pickett et al., 2002), to be associated with injury in adolescents. There seems to be some evidence that young people, who report behavioural problems, are more likely than those, who did not report behavioural problems, engage in injury related behaviour such as engaging in a physical fight, get involved in risk behaviour (e.g., swimming) after drinking, and rarely or never use seat belts (Barrios, Everett, Simon, \& Brener, 2000; Starkuviene \& Zaborskis, 2005). Moreover, truancy was associated with increased risk of injury, as also found among African school children (Peltzer, 2008). It is possible that truant school children are more likely to engage in behaviours (such as violence, illegal road behaviours, drug, and alcohol use) that contribute to the likelihood of an injury, as found in a study among Australian adolescents (Buckley, Chapman, \& Sheehan, 2012).

\section{Limitations of Study}

This study had several limitations. Firstly, the GSHS only includes adolescents who are in school. School-going adolescents may not be representative of all adolescents in a country as the prevalence of injury and associated risk behaviour may differ between the two groups. Furthermore, this study was based on data collected in a cross sectional survey. We cannot, therefore, ascribe causality to any of the associated factors in the study. Finally, the analysis was limited to the risk factors included in the GSHS. There are some other potentially important risk and protective factors (Mytton et al., 2009; Pickett et al., 2006) that could be associated with the occurrence of injury that were not measured.

\section{Conclusions}

In this study a high annual injury prevalence was found among adolescents in seven Caribbean countries. Several risk factors were identified which can be utilized in reaching these young people for change strategies in injury prevention programmes.

\section{Acknowledgements}

We acknowledge the World Health Organization (Geneva) and the Centers for Disease Control and Prevention (Atlanta) for making the data available for analysis, and the country coordinators from Antigua and Barbuda (Cleo Clothilda Hampson), Dominica (Joan Henry), Grenada (Dr. Christine La Grenade), Jamaica (Ellen Campbell Grizzle), St Lucia 
(Cyprian Yarde), St Vincent and the Grenadines (Pasty Wyllie) and Trinidad and Tobago (Lawrence Tobago), for their assistance in collecting the Global School-based Student Health Survey data. We also thank the Ministries of Education and Health and the study participants for making the Global School Health Survey in the seven Caribbean countries possible. The governments of the respective study countries and the World Health Organization did not influence the analysis nor did they have an influence on the decision to publish these findings.

\section{References}

Alonge, O., \& Hyder, A. A. (2014). Reducing the global burden of childhood unintentional injuries. Archives of Diseases in Childhood, 99(1), 62-9.

Anatol, T. (1985). A survey of children with burns in South Trinidad. West Indian Medical Journal, 34(1), 29-37

Arscott-Mills, S., Gordon, G., McDonald, A., Holder, Y., \& Ward, E. (2002). A profile of injuries in Jamaica. Injury Control and Safety Promotion, 9(4), 227-34.

Balan, B., \& Lingam, L. (2012). Unintentional injuries among children in resource poor settings: where do the fingers point? Archives of Diseases in Childhood, 97(1), 35-8.

Barrios, L. C., Everett, S. A., Simon, T. R., \& Brener, N. D. (2000). Suicide ideation among US college students. Associations with other injury risk behaviours. Journal of American College Health, 48, 195-8.

Buckley, L., Chapman, R., \& Sheehan, M. (2012). Adolescent involvement in anti-social and delinquent behaviours: predicting future injury risk. Accident Analysis and Prevention, 48, 518-22.

Centers for Disease Control (CDC) (2010). The Global School and Health Survey background. Retrieved from http://www.cdc.gov/gshs/ background/index.htm at 15 April 2010.

Hasbrouck, L. M., Durant, T., Ward, E., Gordon, G. (2002). Surveillance of interpersonal violence in Kingston, Jamaica: an evaluation. Injury Control \& Safety Promotion, 9(4), 249-53.

Le Franc, E., Samms-Vaughan, M., Hambleton, I., Fox, K., \& Brown, D. (2008). Interpersonal violence in three Caribbean countries: Barbados, Jamaica, and Trinidad and Tobago. Revista Panamericana de Salud Pública, 24(6), 409-21.

Mytton, J., Towner, E., Brussoni, M., \& Gray, S. (2009). Unintentional injuries in school-aged children and adolescents: lessons from a systematic review of cohort studies. Injury Prevention, 15(2), 111-24.

Peltzer, K. (2008). Injury and social determinants among in-school adolescents in six African countries. Injury Prevention, 14(6), 381388.

Peltzer, K. \& Pengpid, S. (2012) Injury and social correlates among in-school adolescents in four Southeast Asian countries. International Journal of Environmental Research and Public Health, 9(8), 2851-2862

Perel, P., Casas, J. P., Ortiz, Z., \& Miranda, J. J. (2006). Noncommunicable diseases and injuries in Latin America and the Caribbean: time for action. PLoS Medicine, 3(9), e344.

Pickett, W., Schmid, H., Boyce, W. F., Simpson, K., Scheidt, P. C., Mazur, J...Harel, Y. (2002). Multiple risk behavior and injury: an international study of youth in 12 countries. Archives of Pediatric Adolescent Medicine, 156, 786-793.

Pickett, W., Molcho, M., Simpson, K., Janssen, I., Kuntsche, E., Mazur, J.... Boyce, W. F. (2005). Cross national study of injury and social determinants in adolescents. Injury Prevention, 11, 213-8.

Pickett, W., Dostaler, S., Craig, W., Janssen, I., Simpson, K., Shelley, S.D., Boyce, W. F. (2006). Associations between risk behavior and injury and the protective roles of social environments: an analysis of 7235 Canadian school children. Injury Prevention, 12, 87-92.

Ramroop, S., Turner, M. C., Bynoe, R., Garner, M. J., Clarke, R., Krewski, D., \& Francis, M. (2009). Injury surveillance in Trinidad: an accident and emergency based injury surveillance system at the San Fernando General Hospital. West Indian Medical Journal, 58(2), 118-23.

Ricketts, P., Bergeron, M., Emmanuel, R., \& Smith, M. (2010). Trends in motor vehicle crash mortality in a small island developing state - the case of Dominica, 2000-2009. Injury Prevention, 16, A243 doi:10.1136/ip.2010.029215.866.

Soyibo, K., \& Lee, M. G. (2000). Domestic and school violence among high school students in Jamaica. West Indian Medical Journal, 49(3), 232-6.

Starkuviene, S., \& Zaborskis, A. (2005). Links between accidents and lifestyle factors among Lithuanian schoolchildren. Medicina (Kaunas), 41(1), 73-80.

St Bernard, G., \& Matthews, W. (2003). A contemporary analysis of road traffic crashes, fatalities and injuries in Trinidad and Tobago. Injury Control and Safety Promotion, 10(1-2), 21-7.

Ward, E., McCartney, T., Arscott-Mills, S., Gordon, N., Grant, A., McDonald, A. H., \& Ashley, D. E. (2010). The Jamaica Injury Surveillance System: a profile of the intentional and unintentional injuries in Jamaican hospitals. West Indian Medical Journal, 59(1), 7-13. 